Scott, N., Le, D., Zhang, R. and Moyle, B. (2017 Accepted) A review of eyetracking research in tourism, Current Issues in Tourism. 


\section{A review of eye-tracking research in tourism}

Noel Scott ${ }^{\mathrm{a} *}$ Dung Le ${ }^{\mathrm{a}}$, Rui Zhang ${ }^{\mathrm{a}}$ and Brent Moyle ${ }^{\mathrm{a}}$

Griffith Institute for Tourism, Griffith University, Gold Coast Campus, 58

Parklands Drive, Southport, Queensland, 4222, Australia.

*Corresponding author email: noel.scott@griffith.edu.au 


\section{A review of eye-tracking research in tourism}

This study provides a review of eye-tracking as a technique for measurement of attention. The review discusses its theoretical basis, advantages and disadvantages, data collection procedures, analysis methods and application in tourism and hospitality. Areas for further research in tourism and hospitality are provided based on a systematic review of tourism research using eye-tracking.

Keywords: eye-tracking, tourism, attention, marketing

\section{Introduction}

Visual attention is a key topic in tourism research (Wang \& Sparks, 2016). Due to the intangibility of tourism experience, visual components including pictures and video are important in shaping the destination image (Feighey, 2003) which in turn influences tourist behavioral intentions. Indeed, visual attention is central to many aspects of tourism such as sightseeing, wayfinding, and interpretation. However, tourists are exposed to thousands of pieces of information, television and radio advertisements, Internet sites and other marketing stimuli as well as having to deal with normal minute by minute interactions with other people, and the world around them (Davenport \& Beck, 2001). Their brains are unable to process all these stimuli and instead rely on attentional processes to focus their mental capacities on priorities relevant to their goals. Attentional processes influence perception by directing overt visual attention to only a few of many possible stimuli in the environment. These attentional capabilities have developed as they provide evolutionary advantages such as better noticing dangerous animals, reading facial expressions, identifying goal related stimuli and allowing concentration on stimuli relevant to important problems. People are conscious of some but not all of our attentional processes. Davenport and Beck (2001, p. 20) define attention as "focused mental engagement on a particular item of information. Items come into our awareness, we attend to a particular item, and then we decide whether to act.” This definition focuses on consciously directed attention. However, many attentional processes, including most of our normal eye movement, are beyond our conscious control. If we consider both conscious and unconscious visual processes, attention may be considered as selectivity in visual perception.

Eye-tracking is a relatively new technique for study of visual attention and perception in tourism research. Previous studies used self-report methods to evaluate the effectiveness of visual 
advertisements after the campaign had been implemented (Kim, Hwang, \& Fesenmaier, 2005; Morgan, Hastings, \& Pritchard, 2012). In order to design better marketing campaigns`, tourist responses to visual advertising may be evaluated objectively before the implementation stage (Scott, Green, \& Fairley, 2016). The study of eye movements has been used in psychology for around a hundred years, and more recently in a number of other disciplinary areas including computer science, engineering and human factors, marketing, and neuroscience (Duchowski, 2002). The recent application in these diverse disciplines of equipment and methods developed in psychology for tracking the movements of the eyes is due to recent technological developments. Eye-tracking equipment that was cumbersome, time-consuming, and expensive has recently been transformed into devices that are unobtrusive and wearable, and which produce data that can be rapidly analysed using specific software programs.

This paper aims to review the literature on the application of eye-tracking to the tourism and hospitality research. In this review, we examine how eye movements are used to provide a novel source of data about what we pay visual attention to, and how this information can be used to improve the usability of websites and other marketing stimuli, understand how we interact with the world around us to find information for wayfinding or look at paintings in a museum, and a host of other applications. Eye tracking techniques assume eye movements indicate the focus of a person's attention (Just \& Carpenter, 1980). This review draws on a number of books and prior reviews of eye-tracking's use in consumer behaviour (Rosa, 2015), education (Lai et al., 2013), information technology (Duchowski, 2002), landscape studies (Lien Dupont, Antrop, \& Van Eetvelde, 2014), marketing (Hui, Fader, \& Bradlow, 2009; Wedel \& Pieters, 2008b), psychology (Mele \& Federici, 2012), reading (Rayner, 1998), and scientific studies of attention and eye movement control (Orquin \& Loose, 2013; Tatler, 2009). In addition, it reviews the recent application of eye-tracking methods in the tourism, hospitality and related sectors in order to provide an introduction for the topic, a structured view of current research and areas for future studies.

\section{Basics of eye-tracking}

When we visually scan our environment, we perceive a continuous and stable image of our surroundings. While our vision appears extremely stable, our eyes are actually in constant motion of two main types; one that directs the fovea to a stimuli (e.g., saccades and smooth pursuits), and 
another that maintains the eye fixed on a stationary stimuli (e.g., fixations). Maximum visual acuity occurs when our eyes are positioned so that the light from a particular part of the visual field (the stimulus) is focused on the eye's fovea, which contains a higher density of sensory neurons. The result is that a particular stimulus receives more cognitive processing. The para-foveal and peripheral sensory neurons surrounding the fovea have a lower density of sensory neurons and therefore only detect stimuli at a lower resolution, providing a sense of an objects general shape colour and motion (Rayner, 1998). Fixation of the fovea provide around half of the visual information sent to our brain but less than eight per cent of our visual field. Each fixation is extremely brief, typically lasting between 200-300 milliseconds (Pan, Zhang, \& Smith, 2011; Rayner, 1998) and contain small jerk-like microsaccades that move the point of fixation slightly. Primary attention is usually directed to the signals received from our fovea. Eye-tracking equipment records the direction the fovea is pointing and hence maps the objects in the visual field to which it is directed. Eye-tracking equipment can also correct for missing data from eyelid blinks.

Fixations are followed by saccades, rapid eye movements traversing 3-5 degrees during which eyes move their focus by around 500 degrees per second. Saccades allow the eye to scan rapidly the visual field to obtain a limited sense of what is happening. While our brain may not receive detailed sensory information about objects during a saccade, it has the capacity to rapidly acquire the "gist" of the visual field and determine object saliency. A number of principles determining the saliency of an object in the visual field and hence the order in which they are fixated upon have been proposed (Goferman, Zelnik-Manor, \& Tal, 2012). An important implication is that we may be aware of an object from our peripheral or para-foveal visual information processing that is not registered by tracking eye fixations.

A number of research techniques have been used to collect data about eye movements when viewing visual stimuli. One of the most common uses analysis of corneal reflections of infrared light invisible to the respondent (Duchowski, 2002). Infrared light reflects off the cornea and onto a measurement sensor enabling the angle of reflection to be calculated. From this angle of reflection, the location of the focus of the eye fovea can be determined and mapped onto an image of the visual field. Because this technique allows continual tracking of where the eye is focusing, it is called eye-tracking. Eye-tracking equipment allows measurement of the location and duration of fixations (circles) and saccades (lines) as shown in Figure 1. 
There are two generic types of eye-tracking data collection equipment: fixed and mobile. Fixed data collection equipment uses an infrared light source and sensors located in a fixed position such as the frame of the computer screen. More recently, lightweight mobile head or glasses mounted devices have become available which can be used when the participant is moving about a museum or street. Collecting and analysing data from mobile eye-tracking devices poses some particular problems which will be discussed below.

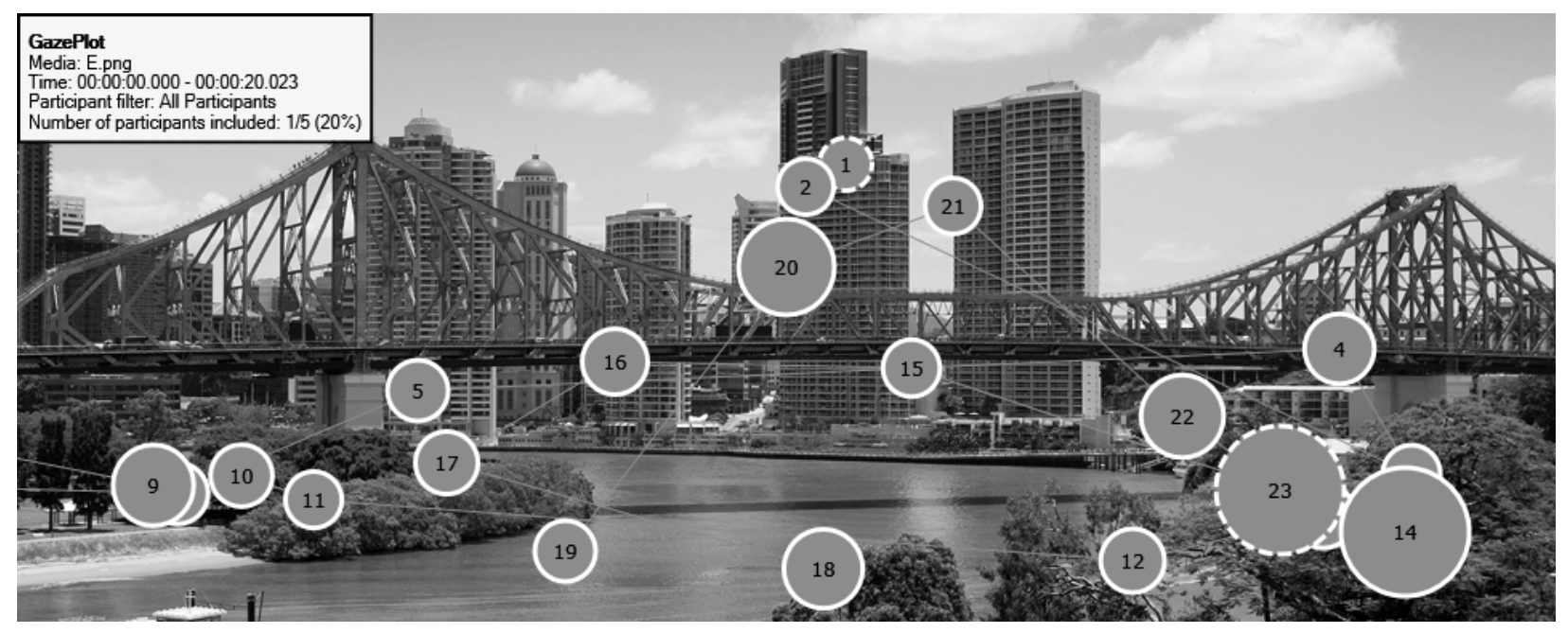

Figure 1. A scanpath-showing fixation (circles) and saccades (lines).

\section{Advantages and disadvantages}

Eye-tracking is a psychophysiological technique typically used to measure attentional processes and has both advantages and disadvantages when compared to other techniques such as self-report questionnaires, thinking aloud protocols, verbal interviews with respondents and so on ( $\mathrm{Li}$, Walters, Packer, \& Scott, Online; Scott et al., 2016). Techniques such as self-report questionnaires rely on conscious reflection and memory that can lead to validity issues as attentional processes are not solely dependent on conscious control, may be beyond a respondent's awareness, and occur too quickly to be individually measured using other techniques. Both conventional and eyetracking techniques also suffer when used in an artificial laboratory environment, where respondents may be aware they are involved in a research study. This may create bias is based on social expectations, political correctness or other factors which may affect eye-tracking techniques to a lesser extent depending of the research design. Mobile eye-tracking research in non-laboratory settings may suffer from a number of data collection issues. On a hot day for example, collecting 
data at the beach is difficult due to infrared reflections from the sand, which overwhelms the infrared camera sensors. When using mobile equipment in a real-world setting, the visual stimuli observed by the participant is always changing and each participant may view a different scene. This complicates the analysis of data but new software allows amalgamation of individual data to produce heat maps in some situations (see below).

There are a number of advantages and disadvantages to use of eye-tracking techniques that must be considered when designing a research project. Eye-tracking methods collect objective data that is less subject to bias. It can provide measures of attention and interest in visual stimuli. However, when a respondent fixates on a stimulus object, this enhances the perception of the associated mental category of the object. While it may be therefore plausible to argue that a lack of attention to an object in the visual field means that the respondent is unaware of it, this assumption only applies when the respondent is unfamiliar with the object (Orquin \& Loose, 2013). Recognition of objects in familiar scenes may only require para-foveal or peripheral vision (Land, 1999). Researchers using eye-tracking should be aware of the literature of perception and attention as cognitive processes (Kuhl \& Chun, 2014). In addition, an eye-tracking study requires careful planning and set up, and generates a considerable volume of data to be analysed. A variety of measures can be used in the analysis of this data as discussed below. Data collection in a laboratory is generally done with one respondent at a time and therefore can occupy a considerable amount of time. A minority of participants (typically 10 to 20\%) are ineligible as their sight cannot be tracked reliably. In addition, eye-tracking equipment and analysis software has a nontrivial cost to purchase and maintain and may require dedicated laboratory space although lower-cost equipment and analysis software is becoming available (Vosskuhler, Nordmeier, Kuchinke, \& Jacobs, 2008). In summary, visual attention is tightly coupled with eye movements, and hence eye-tracking equipment can be used to measure the visual attention process which are otherwise difficult to study.

\section{Key data measures}

To collect and analyse eye-tracking data, it is necessary to specify particular dependent variables or measures from a wide range available. The first or basic metric is the estimated location of the eye gaze at a particular moment in time (i.e., a fixation). Fixations are usually extremely short but can be mapped to specific $\mathrm{X}$ and $\mathrm{Y}$ coordinates on a grid is then matched with a picture of the 
visual stimuli. Fixations are defined as a "relatively stable eye-in-head position within some threshold of dispersion (typically $2^{\circ}$ ) over some minimum duration (typically 200-300 ms), and with a velocity below some threshold (typically 15-100 degrees per second)” (Jacob \& Karn, 2003, p. 581).

While the location of an individual fixation is interesting, it is usual to group fixations based on an area of interest for analysis purposes. An area of interest (AOI) is part of the visual stimuli that is of interest to the researcher and is defined by them. If the researcher is studying brand awareness for example, they may create an area of interest (AOI) around the brand logo. The participant is not aware of the existence of an AOI. Instead, fixations within the AOI boundaries are determined by the analysis software used. Defining AOIs is often an important part of analysing eye-tracking data. In defining AOIs, it is usual to draw the boundaries somewhat larger than the visual feature being examined (padding). The purpose of padding is to allow inclusion of fixations that may be on the boundaries of a visual feature or to cater for the accuracy of the fixation location measurements and the variance in fixation positions across participants. Eye-tracking software uses algorithms to assign fixations to AOIs.

A number of measures are used with AOIs. For example, a fixation count is the number of times an AOI is fixated upon. This measure reflect the importance of the objects within that AOI since salient parts of the stimuli are fixated more frequently (Fitts, Jones, \& Milton, 1950). The total fixations overall is negatively correlated with search efficiency and hence more fixations are required for difficult tasks (Goldberg \& Kotval, 1998). The salience of an AOI is measured by the proportion of respondents who fixate on it. The shorter the time taken to first fixate on an AOI the more impressive or salient it is. Gaze Duration measures the duration of all fixations within an AOI and the length of the first gaze is used to measure interest and engagement. A scan path is a sequence of fixations and saccades and can measure the organizational efficiency of elements in a stimulus. Less efficient organization of elements of a website is indicated by longer scan paths length or duration (Goldberg \& Kotval, 1999). A heat map is used to visualise elements of a stimulus that a number of participants (or one participant a number of times) have attended to (Bojko, 2009). It can be created by amalgamating the fixation duration data across all participants onto an image of the stimulus. A heat map is colour coded to distinguish areas more or less intensively viewed. These and other measures are discussed in Lai et al. (2013). Analysis of mobile 
eye-tracking data can be problematic as each respondent may experience a different visual environment as they move around. Software is now available to combine participant's mobile scanpath data together to create a heatmap. The software maps each persons individual gaze data onto a photo using image recognition software.

A variety of different indicators and rules of thumb to measure the impact of a visual display have been identified. Time to first fixation on an AOI indicates its relative salience, first total gaze duration indicates interest in the stimulus, and repeatedly gazing at an AOI may indicate its influence on attention (Bebko, Sciulli, \& Bhagat, 2014).Data collection and analysis

Data may be collected in a laboratory or a non-laboratory setting. In a laboratory setting, ambient lighting, noise, distractions, and temperature can be controlled to provide a reproducible evaluation environment. The authors use an eye-tracking system with a $96 \mathrm{dpi}, 17$ " monitor having a resolution setting of 1024 x 768 pixels connected to a computer. The monitor frame contains an unobtrusive integrated sensor (e.g., high-resolution camera and near infrared light-emitting diodes). The eye-tracker determines the position of the participant's eyes at 50 Hertz (50 times per second). Mobile eye-tracking equipment used by the authors consists of a set of glasses connected to a small data processing and storage unit. This system measures eye movements in real-time and then allows downloading of the data for analysis. Mobile equipment can also be used with skin conductance or other types of monitoring equipment.

Eye-tracking studies generally use relatively few participants, much like psychophysics or physiology studies (Goldberg \& Wichansky, 2002). Usability experiments using goal-directed searching tasks require a smaller sample than undirected browsing. Representative scan paths may be determined for search tasks using 27 participants (Eraslan, Yesilada, \& Harper, 2016). A metaanalysis of eye-tracking research on differences between experts and novices found an average cell size of 11 . Table 1 summarizes the sample size used in previous eye-tracking studies. Overall, designs have used between 12-63 participants.

Table 1. Eye-tracking study topics and sample size.

\begin{tabular}{|l|l|l|}
\hline Study & Topic & Sample \\
\hline
\end{tabular}




\begin{tabular}{|l|l|l|}
\hline & & size \\
\hline Atalay, Bodur, and Rasolofoarison (2012) & Location of material on brochure racks or shelves. & $63 / 84$ \\
\hline Bebko et al. (2014) & Advertisement effectiveness & 63 \\
\hline Chua, Boland, and Nisbett (2005) & Effect of culture on image recognition & 52 \\
\hline Eghbal-Azar and Widlok (2012) & Attention to displays in museums & 16 \\
\hline Hernandez-Mendez and Munoz-Leiva (2015) & Online tourism advertising effectiveness & 30 \\
\hline Marchiori and Cantoni (2015) & Online tourism website navigation & 28 \\
\hline Green, Murray, and Warner (2011) & Olympic website advertising effectiveness & 21 \\
\hline Hao, Tang, Yu, Li, and Law (2015) & Online advertising effectiveness & 53 \\
\hline $\begin{array}{l}\text { Kiefer, Giannopoulos, Kremer, Schlieder, } \\
\text { and Raubal (2014) }\end{array}$ & How long do people look at a view & 12 \\
\hline Li, Huang, and Christianson (2016) & Effect of text on attention & 37 \\
\hline Pan et al. (2011) & Online travel agency user search strategy & 41 \\
\hline Pan, Zhang, and Law (2013) & Online travel agency user choice strategy & 16 \\
\hline Pan et al. (2004) & Website viewing & 30 \\
\hline Scott et al. (2016) & Advertising & 25 \\
\hline Wang and Sparks (2016) & Cultural effects on image evaluation \\
\hline Yang (2012) & Restaurant menus & \\
\hline & & 30 \\
\hline
\end{tabular}

A typical eye-tracker's measurement error when viewing a screen 50 centimeters away has been estimated at less than half a centimetre (less than 1 degree) but may be greater toward the edge of the stimulus (Goldberg \& Helfman, 2010). Mobile and fixed eye-tracking equipment may have similar measurement errors. It is therefore important that the equipment is calibrated for each participant before the experiment starts (Blignaut \& Beelders, 2012; Holmqvist, Nyström, \& Mulvey, 2012). Typically, calibration is done through displaying fixation targets on a screen, which the participant follows with their eyes. An experiment should consist of discrete, short tasks followed by a break to avoid boredom or fatigue (Goldberg \& Helfman, 2010). 
Data analysis begins by use of software to identify fixations and saccades and extract this data. The software algorithms use various techniques, such as the number of gaze-points within a defined radius, or eye movement velocity, to identify a fixation (Salvucci \& Goldberg, 2000). Typically, a fixation time of around $200 \mathrm{~ms}$ is used and small changes in this value may change the number of fixations identified. Researchers should therefore report choices of these parameters in their papers. Analysis of data may be based on hypotheses and psychological theory or entirely on describing patterns of activity.

\section{Aims and significance of this review}

In response to the growing interest of eye-tracking technique in tourism research, this study aims to map out how eye-tracking has been used in tourism research in order to identify opportunities of employing eye-tracking in future research. This review papers make several contributions to the body of knowledge. Firstly, as new research technologies have attracted the attention among tourism academics (Li, Scott, \& Walters, 2015), it lacks a systematic review of eye-tracking research in tourism. Eye-tracking is still a modern research technique which has great potential to explore the unconscious attentional processes. This review paper is hence useful as a guide for tourism researchers who plan to employ eye-tracking in future research. Secondly, this paper discusses applications of eye-tracking application in exploring visual processing from marketing and psychology research. A broad view of how eye-tracking can be used to replace self-reports method in a number of promising research directions is provided.

\section{Research method}

Systematic quantitative approach

This study employed a systematic quantitative approach to review eye-tracking research in tourism and hospitality areas (Pickering \& Byrne, 2014). The search terms are firstly identified including “eye-tracking” or “eye movement” or “eye measurement” and “tourism” or "hospitality”. Based on prior tourism review publications, important tourism databases are EBSCO Host (Hospitality and Tourism Complete), Science Direct (Elsevier), Sagepub and Leisure tourism database (Durko \& Petrick, 2013; Yang, Khoo-Lattimore, \& Arcodia, 2017). To ensure the quality of the review paper, only academic papers published in English peer-reviewed journal are included. In total, 102 papers are selected imported into Endnote. After deleting duplicating references and irrelevant 
papers which only mention but do not use eye-tracking method, there are 17 papers remaining for inclusion in this systematic quantitative literature review. The limited number of papers indicates that eye-tracking remains relatively understudied in tourism research.

\section{Data analysis}

All 17 papers were then imported into Leximancer for further qualitative analysis. This content analysis software counts word frequency and also analyse the meanings within passages of text by extracting the main concepts and ideas (Scott \& Smith, 2005). Leximancer is useful for identifying concepts frequently mentioned in literature reviews (Dann, 2010; Indulska, 2011). Visual concept maps were generated in this study in order to gain greater insights on how eye-tracking has been used in tourism research. Several steps in Leximancer operation are required to achieve interpretable results: (1) meaningless words such as "able”, “code”, “according” were eliminated; (2) similar concepts were grouped together and coded as a concept; (3) a series of repeated analysis to explore and modify settings as well as to explore the main concepts within the text were undertaken; (4) relevant concepts were finally visualised into different themes (Tseng, Wu, Morrison, Zhang, \& Chen, 2015).

Four themes identified from the concept map (Figure 2) were classified in order of importance including information attention (628 occurrences), eye-tracking measures (460 occurrences), advertising perception (323 occurrences) and research areas (239 occurrences). These themes represent how eye-tracking is discussed in tourism research. Two important applications of eyetracking are to assess attention to information and advertising. 


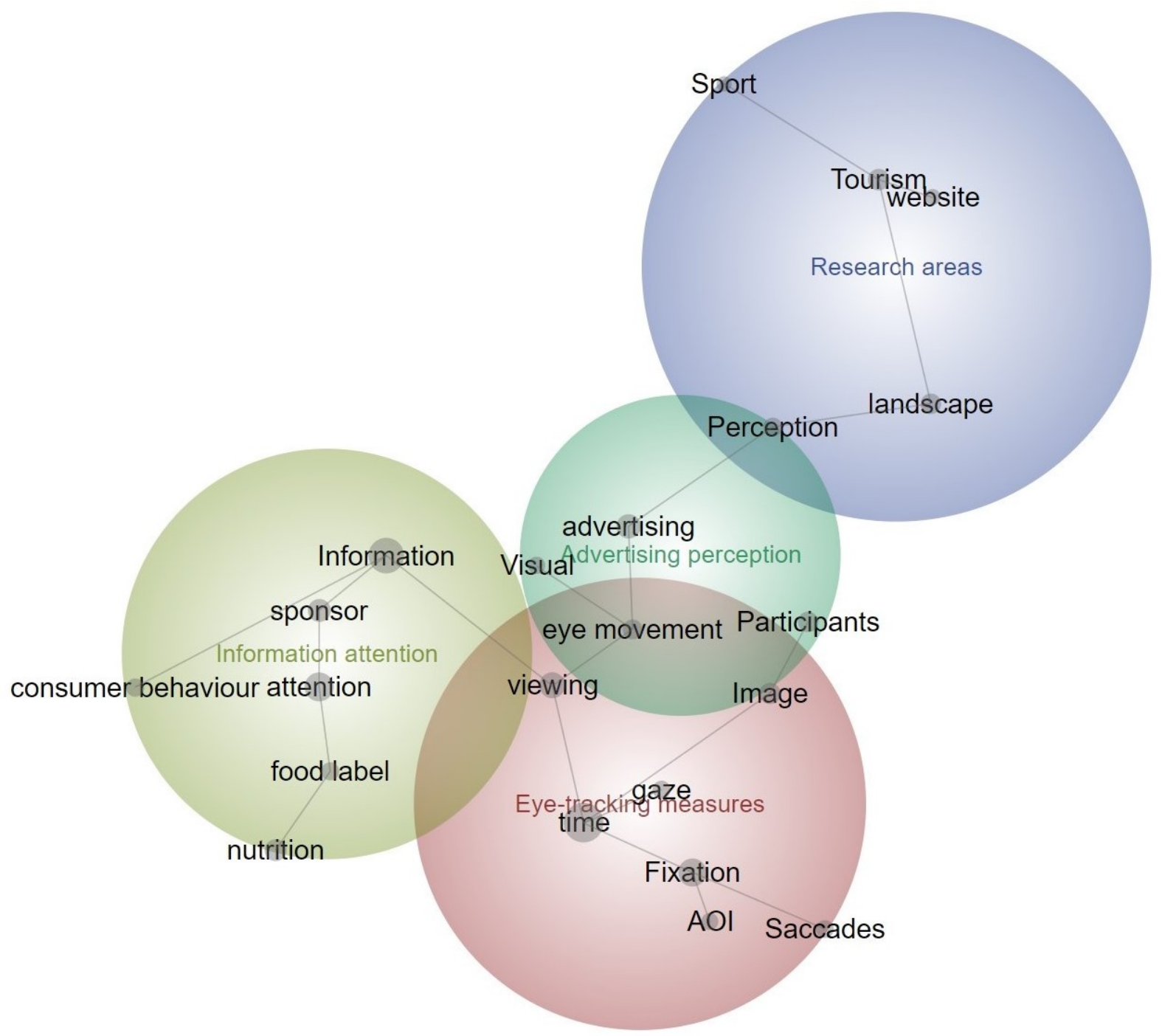

Figure 2. Concept map created from Leximancer.

\section{Findings}

Eye-tracking studies have been used to study attention, involvement, attitude formation, recognition, and recall (Aribarg, Pieters, \& Wedel, 2010; Pieters \& Wedel, 2004). Wedel and Pieters (2008b) have reviewed use of eye-tracking in advertising studies (print, TV, and banner), health and nutrition warnings (Krugman, Fox, Fletcher, Fischer, \& Rojas, 1994), branding (Janiszewski, 1993), and choice, in-store marketing (Chandon, Hutchinson, Bradlow, \& Young, 2009) merchandise displays (Huddleston, Behe, Minahan, \& Fernandez, 2015) and shelf search behaviors (Pieters, Hans, \& Allen, 1995; Pieters, Rosbergen, \& Wedel, 1999; Pieters \& Warlop, 
1999; Pieters \& Wedel, 2007). A variety of studies in particular areas are available such as reading (Rayner, Rotello, Stewart, Keir, \& Duffy, 2001). In tourism, researchers seem to focus on two important themes: advertisement perception and consumer attention to marketing information. Important research areas include web usability, landscape research and sport performance.

\section{Use of eye-tracking measures}

In tourism research, eye-tracking has been used mostly to measure the time participants spend looking at stimuli including visual advertising, food label, and images. Viewing time can be tracked directly (Nelson, Graham, \& Harnack, 2014; Wolfson, Graham, \& Bleich, 2017) or indirectly by measuring fixation measures. Major fixation measurements used are fixation count and/or fixation duration (Antúnez, Giménez, Maiche, \& Ares, 2015; Ellert, Schafmeister, Mueller, Dallwig, \& Phelan, 2014; Green et al., 2011; Samant \& Seo, 2016). The dwell time (Berenbaum \& Latimer-Cheung, 2014) or glance duration (Breuer \& Rumpf, 2012) or total viewing time (Q. Li et al., 2016) can be calculated based on these fixation measures in accordance with the authors' measurement objectives. The second common eye-tracking measure is saccade. (Di Stasi, Marchitto, Antolí, Baccino, \& Cañas, 2010; Scott et al., 2016) for further exploring the visual possessing. The use of heat maps (Li et al., 2016; Pan et al., 2011; Potocka, 2013; Samant \& Seo, 2016) or scan-path/ gaze plots (Hellmann, Yeow, \& De Mello, 2017; Scott et al., 2016; Wang \& Sparks, 2016) helps researchers to visualise research findings. Researchers define specific AOI in order to evaluate participants' attention to these areas.

\section{Information attention}

Eye-tracking is used to study human attentional processing of stimuli. In tourism research, academics have employed eye-tracking to explore how participants pays attention to marketing messages, or information such as calorie information on food labels (Nelson et al., 2014; Wolfson et al., 2017), sustainability related labels (Samant \& Seo, 2016), front-of-package nutrition labels (Antúnez et al., 2015) or sponsor information in sport telecasts (Breuer \& Rumpf, 2012). Interestingly, attentional bias can also be evaluated by eye-tracking. Two dimensions of attentional bias duration bias and direction bias were measured by comparing fixation and saccades in neutral versus gambling-related pictures (Grant \& Bowling, 2015). 


\section{Advertising perception}

Instead of subjective self-reports, eye-tracking offers an objective measurement to study how tourists perceive visual tourism advertisements. In order to improve advertisement effectiveness, tourism academics have investigated the influence of textual presentation order and graphical presentation on judgments (Hellmann et al., 2017), image characteristics and ethnicity (Wang \& Sparks, 2016), text advertisement versus advertisement with block images (Scott et al., 2016), tourism photographs with text (Li et al., 2016) gain-framed messages versus loss-framed messages (Berenbaum \& Latimer-Cheung, 2014) and imbibing alcohol (Ellert et al., 2014) on advertising perception. In general, block images advertisement were more effective in attracting and retaining attention compared to the text in advertisements (Scott et al., 2016). Text increases consumer attention toward the tourism advertisement, in particular when the text is in the participants' native language (Li et al., 2016). Differences in advertisement perception has been noted between groups of participants from different cultures (Wang \& Sparks, 2016).

In the tourism literature, advertising effectiveness research is often underpinned by hierarchical decision making models such as the destination advertising response (DAR) (Choe, Stienmetz, \& Fesenmaier, 2014) or Attitude-Interest-Desire-Action (AIDA) model (Barry, 1987). However, these models consider attention as an open or closed gate leading to more detailed processing of passively acquired information (Orquin \& Loose, 2013) rather than a continuous coordinating process that reflects current goals (LaBerge, 1995). Recent research has extended this notion of hierarchy (temporal sequence) by shifting focus to a set of core constructs: attention, affect, memory, and desirability. These constructs can affect advertising success independently or in combination (Venkatraman et al., 2015). Eye-tracking has been used to investigate online accommodation purchase intention, finding that images, semantic message, price and layout influence hotel choice. Some studies have found that during purchase consideration, pictures such as brand image and symbols attract more attention than word description and comment (Noone \& Robson, 2014) or online hotel review text (Aicher et al., 2016). Price incentives also attract attention (Tzuaan, Sivaji, Yong, Zanegenh, \& Shan, 2014). In later purchase stages, tourists concentrate more on third-party consumer evaluations (Noone \& Robson, 2016). In contrast, Hernandez-Mendez and Munoz-Leiva (2015) found that travellers devoted more attention to semantic information rather than pictures when viewing hotel web-ads, and they were more likely 
to attend to static ads on first time viewing. Similarly, they found that word content rather than destination pictures dominated visitors' visual attention.

\section{Research areas}

There are several main areas of tourism research that have employed eye-tracking methods. Sport researchers are active in adopting eye-tracking methods. Sports research aims to improve player performance in basketball shooting (Steciuk \& Zwierko, 2015), to map mental workload components (Di Stasi et al., 2010), to improve viewers' reception of sponsorship information in sport telecasts (Breuer \& Rumpf, 2012) and to measure attention to physical activity ads (Berenbaum \& Latimer-Cheung, 2014). Tourism researchers instead study perception of landscape images (Li et al., 2016; Potocka, 2013) or photographs of tourism activities (Wang \& Sparks, 2016).

Website usability is an important topic in tourism research. Website usability studies using eyetracking methods examine how people use websites and the clarity of their interaction with it (Benbunan-Fich, 2001). A number of eye-tracking studies of webpages were identified (Bergstrom \& Schall, 2014; Djamasbi, Siegel, \& Tullis, 2010; Drèze \& Hussherr, 2003; Ert \& Fleischer, 2016; Goldberg, Stimson, Lewenstein, Scott, \& Wichansky, 2002; Hao et al., 2015; Hernandez-Mendez

\& Munoz-Leiva, 2015; Lorigo et al., 2008; Marchiori \& Cantoni, 2015; Pan et al., 2004). In tourism, eye-tracking has been used to study website browsing behaviour finding that respondents' scan paths are affected by site structural and visual complexity (Pan et al., 2004). Later studies have looked at the website of an online travel agency (Pan et al., 2011) and online sports event (Green et al., 2011). These studies found that male users preferred simpler interfaces due to their attention to utilitarian (e.g. layout, navigation, price, etc.) rather than hedonic factors, but this is reversed for female purchasers. Online accommodation choice is impacted by attention to hedonic images (Pan et al., 2013) but users' information search is mostly utilitarian in nature (Pan et al., 2011). Eye-tracking studies of destination choice before travelling has found that purchase selection is influenced by information supply channel characteristics (Mariussen, Von Ibenfeldt, \& Vespestad, 2014). 


\section{Conclusions and future research}

The above discussion highlights use of eye-tracking techniques as an active area of research that is being applied to study tourism and hospitality phenomena. The main areas for eye-tracking research studies are: advertising perception and especially website design and effectiveness, and consumer attention to specific messages or information on product labels. Websites are a critical means of attracting visitors to a destination and use of eye-tracking techniques can supplement existing evaluation measures (Kim et al., 2005; Kim \& McMillan, 2008; Siegel \& Ziff-Levine, 1990). Eye-tracking is also a promising method in sport research for improvement of player performance or evaluation of viewers' attention to sport events.

This review of the eye-tracking literature suggests that while objective measures of attention are useful, they are often used in multimethod studies along with self-report measures and other subjective indicators. Eye-tracking studies, like other methods have advantages and disadvantages. In general, eye-tracking studies are more labour and time-intensive, may suffer from criticism of their external validity due to laboratory conditions and small sample size. However, recent reductions in hardware and software costs, the availability of mobile eye tracking glasses and better analysis software are addressing these issues.

Robson and Noone (2014) have identified the main areas for use of eye tracking techniques: choice analysis, distribution channel conversion analysis, facility design analysis and employee development. Choice analysis techniques may be applied to evaluation of restaurant menus (Ozdemir \& Caliskan, 2015; Yang, 2012) to test response to the offering list. Eye tracking can add to the analysis of customer selections (clicks) in studying the effectiveness of electronic distribution channels. Eye-tracking could enhance facility and experience design by testing consumer reactions to new hotel layouts or wayfinding in airports or public spaces. In future, it may be possible to track our interaction with computer simulations in virtual reality by recording eye movements. Wearable eye trackers may become an important assessment tool for measuring staff performance. There is evidence that experts and novices pay attention to different objects (Dupont, Antrop, \& Van Eetvelde, 2015) and analysis of a new employee's interaction with their environment using eye-tracking may provide valuable training feedback. Researchers have used eye-tracking to study how rock climbers develop a climbing strategy (Grushko \& Leonov, 2014). 
In addition to these above research directions, eye-tracking should be further employed to study tourist attentional processing. Attention can be allocated endogenously or exogenously (bottomup) (Posner, 1980; Wedel \& Pieters, 2008a). Endogenous attention (top-down) is considered to be controlled by a person's goals (Rosa, 2015). A person who is thinking of a holiday in Greece will be more likely to notice Greek holiday advertising. Attention can also be reflexive or exogenous whereby external stimuli capture attention through its colour, contrast, luminance or movement. The combination of top-down and bottom-up mechanisms provides a basis for understanding eye movements. This model provides an explanation for why task instructions during an eye-tracking study affect the object fixated (Duchowski, 2002, p. 458). Task relevance has been identified as the primary driver of attention in, for instance, natural tasks (Orquin \& Loose, 2013, p. 192). Studies on expertise effects on comprehension of visualizations, show that experts have longer saccades, shorter fixation durations, more fixations in salient AOIs, and shorter first fixations on salient AOIs, when compared with novices. Therefore participants' goals must be considered by researchers as will be effect top-down attention (Rayner et al., 2001). This has implications for understanding the tourist gaze. While most tourism research to date has only investigated the bottom-up attention and tested different marketing stimuli, it could be possible to examine what naive viewers look at compared to those who have had an instruction (goal). Bottom-up attention may be related to bias towards viewing faces and body parts (Ro, Friggel, \& Lavie, 2007).

The application of mobile eye-tracking in scene viewing and visitor aesthetic evaluation is clearly a central area topic in design of tourism experiences but until recently has been considered too complex for objective measurement. On site studies have examined museum experiences (Toyama, Kieninger, Shafait, \& Dengel, 2011) and viewing a city panorama (Kiefer et al., 2014). Although it is more difficult to control for experiments outside the lab, field application of eyetracking has been gradually received attention (Green et al., 2011; Pan et al., 2011). Attention measures found from eye-tracking studies provide one option for evaluation of interest and fascination of natural and man-made aesthetic objects. When viewing natural scenery, the "gist" or overview of the scene is comprehended with the first fixations, with later fixations providing more detail (Rayner, 1998). Several measures for the evaluating the relative salience of AOIs are available (Henderson, Weeks Jr, \& Hollingworth, 1999) although task has an effect on natural scene viewing eye movement. Interestingly, eye-tracking patterns within a scene can be predicted by the pattern of colour, intensity and orientation which together create a saliency map of a scene 
(Milosavljevic \& Cerf, 2008). This saliency map is then used to subconsciously to determine a preferred scan path. Software programs are available that provide saliency maps as computational modelling output. Studies have examined how pleasant or unpleasant images capture attention using time to first fixation and gaze duration in the first $500 \mathrm{~ms}$. Preferential or selective attention refers to the probability that an emotional stimulus is attended to, and to the amount of attentional resources allocated to this stimulus, relative to a non-emotional stimulus, when both are presented simultaneously (Calvo \& Lang, 2004).

A novel area that might be interesting for tourism is eye-tracking application in evaluating tourists' interaction with virtual products such as digital tourist guides, route planning or usage of cartographic maps, etc. Eye-tracking has been used for virtual scene evaluation, particularly in virtual cultural heritage contexts (Gena, De Carolis, Kuflik, \& Nunnari, 2016; Netek, 2011) such as museums, ancient architecture, and historical relics. Participants' experience of virtual museums has been measured via eye-tracking (Bastanlar, 2007) indicating that visitors preferred semantic information, 360 degree visual angles and floor map. Naspetti et al. (2016) found that a viewer's attention was influenced by added augmented reality applications. Eye-tracking has been used to evaluate the aesthetics of lake sightseeing (Potocka, 2013) and the educational use of 3D techniques for a virtual tour of a vanished village. Compared with these effects, hotel virtual tours generated low interest (Pan et al., 2011). Likewise, heritage attractions impact drivers' vision (Antonson, Ahlström, Mårdh, Blomqvist, \& Wiklund, 2014), and drivers’ pay attention to tourism information signs (Neill, Hurwitz, \& Olsen, 2015). Tourists' route selection on site has been studied (Nevelsteen, 2013), and Afrooz, White, and Neuman (2014) found that architecture is of less interest to active travellers, while animated signs attracted attention.

Eye-tracking studies have shown that visitor characteristics including demographics (e.g. age, gender, and occupation), cultural background (e.g. ethnic, knowledge, and country of origin) (Hernandez-Mendez \& Munoz-Leiva, 2015; Pan et al., 2013; Tzuaan et al., 2014; Wang \& Sparks, 2016), and purpose (e.g. natural or targeted, expect or non-expert) (Li et al., 2016; Naspetti et al., 2016; Sang, Tveit, Pihel, \& Hägerhäll, 2016) affect their attention to and interaction with their environment. Further studies of cultural differences in attention appear useful area for research. Last but not least, use of eye-tracking in conjunction with techniques to measure emotion offers considerable opportunities of contributable research in tourism. Some researchers have examined 
objective measures of emotional responses in tourism (Li et al., 2015; Ma, Campos, Li, Gardiner, \& Scott, 2016; Sivaji, Tzuaan, Yang, \& bin Ali Russin, 2014) and it is possible to combine eye tracking with psychophysiological measures such as skin conductance, heart rate variability and so on. This has application in the studies of art appreciation (Locher, Krupinski, Mello-Thoms, \& Nodine, 2007) and aesthetic reaction to natural scenery (Leder, Mitrovic, \& Goller, 2016). Overall eye-tracking has much to recommend it to tourism and hospitality researchers. The application of eye-tracking method in tourism research can further explore how tourists perceive and interact with real tourism scenes as well as virtual products.

\section{References}

Afrooz, A., White, D., \& Neuman, M. (2014). Which visual cues are important in way-finding? Measuring the influence of travel mode on visual memory for built environments. Paper presented at the Universal Design 2014: Three Days of Creativity and Diversity: Proceedings of the International Conference on Universal Design, UD 2014 Lund, Sweden, June 16-18, 2014.

Aicher, J., Asiimwe, F., Batchuluun, B., Hauschild, M., Zöhrer, M., \& Egger, R. (2016). Online Hotel Reviews: Rating Symbols or Text... Text or Rating Symbols? That Is the Question! In A. Inversini \& R. Schegg (Eds.), Information and Communication Technologies in Tourism 2016 (pp. 369-382): Springer.

Antonson, H., Ahlström, C., Mårdh, S., Blomqvist, G., \& Wiklund, M. (2014). Landscape heritage objects' effect on driving: a combined driving simulator and questionnaire study. Accident Analysis \& Prevention, 62, 168-177.

Antúnez, L., Giménez, A., Maiche, A., \& Ares, G. (2015). Influence of interpretation aids on attentional capture, visual processing, and understanding of front-of-package nutrition labels. Journal of Nutrition Education and Behavior, 47(4), 292-299.

Aribarg, A., Pieters, R., \& Wedel, M. (2010). Raising the BAR: Bias adjustment of recognition tests in advertising. Journal of marketing Research, 47(3), 387-400.

Atalay, A., Bodur, H., \& Rasolofoarison, D. (2012). Shining in the center: Central gaze cascade effect on product choice. Journal of Consumer Research, 39(4), 848-866.

Barry, T. (1987). The development of the hierarchy of effects: An historical perspective. Current issues and Research in Advertising, 10(1-2), 251-295. 
Bastanlar, Y. (2007). User behaviour in web-based interactive virtual tours. Paper presented at the 2007 29th International Conference on Information Technology Interfaces.

Bebko, C., Sciulli, L. M., \& Bhagat, P. (2014). Using Eye Tracking to Assess the Impact of Advertising Appeals on Donor Behavior. Journal of Nonprofit \& Public Sector Marketing, 26(4), 354-371. doi: 10.1080/10495142.2014.965073

Benbunan-Fich, R. (2001). Using protocol analysis to evaluate the usability of a commercial web site. Information \& Management, 39(2), 151-163.

Berenbaum, E., \& Latimer-Cheung, A. (2014). Examining the link between framed physical activity ads and behavior among women. Journal of Sport and Exercise Psychology, 36(3), 271-280.

Bergstrom, J. R., \& Schall, A. (2014). Eye Tracking in User Experience Design. US: Morgan Kaufmann Publishers Inc.

Blignaut, P., \& Beelders, T. (2012). The precision of eye-trackers: a case for a new measure. Paper presented at the Proceedings of the Symposium on Eye Tracking Research and Applications, Santa Barbara, California.

Bojko, A. (2009). Informative or misleading? Heatmaps deconstructed Human-computer interaction. New trends (pp. 30-39): Springer.

Breuer, C., \& Rumpf, C. (2012). The viewer's reception and processing of sponsorship information in sport telecasts. Journal of Sport Management, 26(6), 521-531.

Calvo, M., \& Lang, P. (2004). Gaze patterns when looking at emotional pictures: Motivationally biased attention. Motivation and Emotion, 28(3), 221-243.

Chandon, P., Hutchinson, J., Bradlow, E., \& Young, S. (2009). Does in-store marketing work? Effects of the number and position of shelf facings on brand attention and evaluation at the point of purchase. Journal of Marketing, 73(6), 1-17.

Choe, Y., Stienmetz, J., \& Fesenmaier, D. (2014). Prior experience and destination advertising response. Tourism Analysis, 19(3), 351-359.

Chua, H., Boland, J., \& Nisbett, R. (2005). Cultural variation in eye movements during scene perception. Proceedings of the National Academy of Sciences of the United States of America, 102(35), 12629-12633.

Davenport, T., \& Beck, J. (2001). The attention economy: Understanding the new currency of business. Boston, Mass.: Harvard Business Press. 
Di Stasi, L. , Marchitto, M., Antolí, A., Baccino, T., \& Cañas, J. (2010). Approximation of on-line mental workload index in ATC simulated multitasks. Journal of Air Transport Management, 16(6), 330-333.

Djamasbi, S., Siegel, M., \& Tullis, T. (2010). Generation Y, web design, and eye tracking. International Journal of Human-Computer Studies, 68(5), 307-323.

Drèze, X., \& Hussherr, F. X. (2003). Internet advertising: Is anybody watching? Journal of interactive marketing, 17(4), 8-23.

Duchowski, A. (2002). A breadth-first survey of eye-tracking applications. Behavior Research Methods, Instruments, \& Computers, 34(4), 455-470.

Dupont, L., Antrop, M., \& Van Eetvelde, V. (2014). Eye-tracking Analysis in Landscape Perception Research: Influence of Photograph Properties and Landscape Characteristics. Landscape Research, 39(4), 417-432. doi: 10.1080/01426397.2013.773966

Dupont, L., Antrop, M., \& Van Eetvelde, V. (2015). Does landscape related expertise influence the visual perception of landscape photographs? Implications for participatory landscape planning and management. Landscape and Urban Planning, 141, 68-77. doi: 10.1016/j.landurbplan.2015.05.003

Durko, A., \& Petrick, J. (2013). Family and Relationship Benefits of Travel Experiences: A Literature Review. Journal of Travel Research, 52(6), 720-730. doi: $10.1177 / 0047287513496478$

Eghbal-Azar, K., \& Widlok, T. (2012). Potentials and Limitations of Mobile Eye Tracking in Visitor Studies: Evidence From Field Research at Two Museum Exhibitions in Germany. Social Science Computer Review, 31(1), 103-118.

Ellert, G., Schafmeister, G., Mueller, F., Dallwig, S., \& Phelan, S. (2014). The influence of alcohol on advertising perception and recall during a sports viewing experience. European Sport Management Quarterly, 14(2), 153-170.

Eraslan, S., Yesilada, Y., \& Harper, S. (2016). Eye tracking scanpath analysis on web pages: how many users? Paper presented at the Proceedings of the Ninth Biennial ACM Symposium on Eye Tracking Research \& Applications.

Ert, E., \& Fleischer, A. (2016). Mere Position Effect in Booking Hotels Online. Journal of Travel Research, 55(3), 311-321. doi: 10.1177/0047287514559035 
Feighey, W. (2003). Negative image? Developing the visual in tourism research. Current Issues in Tourism, 6(1), 76-85.

Fitts, P., Jones, R., \& Milton, J. (1950). Eye movements of aircraft pilots during instrument-landing approaches. Aeronautical Engineering Review, 9(2), 24-29.

Gena, C., De Carolis, B., Kuflik, T., \& Nunnari, F. (2016). Advanced Visual Interfaces for Cultural Heritage. Paper presented at the Proceedings of the International Working Conference on Advanced Visual Interfaces.

Goferman, S., Zelnik-Manor, L., \& Tal, A. (2012). Context-aware saliency detection. Pattern Analysis and Machine Intelligence, IEEE Transactions on, 34(10), 1915-1926.

Goldberg, J., \& Helfman, J. (2010). Comparing information graphics: a critical look at eye tracking. Paper presented at the Proceedings of the 3rd BELIV'10 Workshop: BEyond time and errors: novel evaLuation methods for Information Visualization, Atlanta, Georgia.

Goldberg, J., \& Kotval, X. (1998). Eye movement-based evaluation of the computer interface. In S. Kumar (Ed.), Advances in occupational ergonomics and safety (pp. 529-532). Amsterdam: IOS Press,.

Goldberg, J., \& Kotval, X. (1999). Computer interface evaluation using eye movements: methods and constructs. International Journal of Industrial Ergonomics, 24(6), 631-645.

Goldberg, J., Stimson, M., Lewenstein, M., Scott, N., \& Wichansky, A. (2002). Eye tracking in web search tasks: design implications. Paper presented at the Proceedings of the 2002 symposium on Eye tracking research \& applications.

Goldberg, J., \& Wichansky, A. (2002). Eye tracking in usability evaluation: A practitioner’s guide. In J. Hyona, R. Radach, \& H. Deubel (Eds.), The Mind's Eye: Cognitive and applied aspects of our eye movement research (pp. 493-516). Amsterdam: Elsevier.

Grant, L., \& Bowling, A. (2015). Gambling attitudes and beliefs predict attentional bias in nonproblem gamblers. Journal of gambling studies, 31(4), 1487-1503.

Green, B., Murray, N., \& Warner, S. (2011). Understanding website useability: an eye-tracking study of the Vancouver 2010 Olympic Games website. International Journal of Sport Management and Marketing, 10(3), 257-271.

Grushko, A., \& Leonov, S. (2014). The usage of eye-tracking technologies in rock-climbing. Procedia-Social and Behavioral Sciences, 146, 169-174. 
Hao, J., Tang, R., Yu, Y., Li, N., \& Law, R. (2015). Visual Appeal of Hotel Websites: An Exploratory Eye Tracking Study on Chinese Generation Y. In I. Tussyadiah \& A. Inversini (Eds.), Information and Communication Technologies in Tourism 2015 (pp. 607-620): Springer International Publishing.

Hellmann, A., Yeow, C., \& De Mello, L. (2017). The influence of textual presentation order and graphical presentation on the judgements of non-professional investors. Accounting and Business Research, 47(4), 455-470.

Henderson, J., Weeks Jr, P., \& Hollingworth, A. (1999). The effects of semantic consistency on eye movements during complex scene viewing. Journal of experimental psychology: Human perception and performance, 25(1), 210-228.

Hernandez-Mendez, J., \& Munoz-Leiva, F. (2015). What type of online advertising is most effective for eTourism 2.0? An eye tracking study based on the characteristics of tourists. Computers in Human Behavior, 50, 618-625. doi: 10.1016/j.chb.2015.03.017

Holmqvist, K., Nyström, M., \& Mulvey, F. (2012). Eye tracker data quality: what it is and how to measure it. Paper presented at the Proceedings of the symposium on eye tracking research and applications.

Huddleston, P., Behe, B., Minahan, S., \& Fernandez, R. (2015). Seeking attention: an eye tracking study of in-store merchandise displays. International Journal of Retail \& Distribution Management, 43(6), 561-574.

Hui, S., Fader, P., \& Bradlow, E. (2009). Path data in marketing: An integrative framework and prospectus for model building. Marketing Science, 28(2), 320-335.

Jacob, R., \& Karn, K. (2003). Eye tracking in human-computer interaction and usability research: Ready to deliver the promises. In R. Radach, J. Hyönä, \& H. Deubel (Eds.), The Mind's Eye: Cognitive and Applied Aspects of Eye Movement Research (pp. 573-605). Amsterdam: Elsevier.

Janiszewski, C. (1993). Preattentive Mere Exposure Effects. Journal of Consumer Research, 20(3), 376-392.

Just, M., \& Carpenter, P. (1980). A theory of reading: from eye fixations to comprehension. Psychological review, 87(4), 329-354. 
Kiefer, P., Giannopoulos, I., Kremer, D., Schlieder, C., \& Raubal, M. (2014). Starting to get bored: An outdoor eye tracking study of tourists exploring a city panorama. Paper presented at the Proceedings of the Symposium on Eye Tracking Research and Applications.

Kim, D., Hwang, Y., \& Fesenmaier, D. (2005). Modeling Tourism Advertising Effectiveness. Journal of Travel Research, 44, 42-49.

Kim, J., \& McMillan, S. (2008). Evaluation of Internet Advertising Research: A Bibliometric Analysis of Citations from Key Sources. Journal of Advertising, 37(1), 99-112.

Krugman, D., Fox, R., Fletcher, J., Fischer, P., \& Rojas, T. (1994). Do adolescents attend to warnings in cigarette advertising? An eye-tracking approach. Journal of Advertising Research, 34, 39-39.

Kuhl, B., \& Chun, M. (2014). Memory and attention. In A. Nobre \& S. Kastner (Eds.), The Oxford handbook of attention (pp. 806-836). Oxford: Oxford University Press.

LaBerge, D. (1995). Attentional processing: The brain's art of mindfulness (Vol. 2): Harvard University Press.

Lai, M., Tsai, M., Yang, F., Hsu, C.-Y., Liu, T., Lee, S. W., . . Tsai, C. (2013). A review of using eye-tracking technology in exploring learning from 2000 to 2012. Educational Research Review, 10, 90-115.

Land, M. (1999). Motion and vision: why animals move their eyes. Journal of Comparative Physiology A, 185(4), 341-352.

Leder, H., Mitrovic, A., \& Goller, J. (2016). How Beauty Determines Gaze! Facial Attractiveness and Gaze Duration in Images of Real World Scenes. i-Perception, 7(4), 1-12.

Li, Q., Huang, Z., \& Christianson, K. (2016). Visual attention toward tourism photographs with text: An eye-tracking study. Tourism Management, 54, 243-258.

Li, S., Scott, N., \& Walters, G. (2015). Current and potential methods for measuring emotion in tourism experiences: a review. Current Issues in Tourism, 18(9), 805-827.

Li, S., Walters, G., Packer, J., \& Scott, N. (Online). Using skin conductance and facial electromyography to measure emotional responses to tourism advertising. Current Issues in Tourism, 1-23. doi: 10.1080/13683500.2016.1223023

Locher, P., Krupinski, E., Mello-Thoms, C., \& Nodine, C. (2007). Visual interest in pictorial art during an aesthetic experience. Spatial Vision, 21(1), 55-77. 
Lorigo, L., Haridasan, M., Brynjarsdóttir, H., Xia, L., Joachims, T., Gay, G., . . Pan, B. (2008). Eye tracking and online search: Lessons learned and challenges ahead. Journal of the American Society for Information Science and Technology, 59(7), 1041-1052.

Ma, J., Campos, A., Li, S., Gardiner, S., \& Scott, N. (2016). Attention, Emotion and Hedonic Service Experiences: Managing and Delivering Services in the Asian Century. Worldwide hospitality and tourism themes, 8(1), 53-60.

Marchiori, E., \& Cantoni, L. (2015). Studying Online Contents Navigation: A Comparison Between Eye-Tracking Technique and Self-Reported Investigation Information and Communication Technologies in Tourism 2015 (pp. 349-359): Springer.

Mariussen, A., Von Ibenfeldt, C., \& Vespestad, M. K. (2014). The typology and role of online information sources in destination image formation: an eye-tracking study. The International Journal of Digital Accounting Research, 14(20), 141-164.

Mele, M., \& Federici, S. (2012). Gaze and eye-tracking solutions for psychological research. Cognitive Processing, 13(1), 261-265. doi: 10.1007/s10339-012-0499-z

Milosavljevic, M., \& Cerf, M. (2008). First attention then intention: Insights from computational neuroscience of vision. International Journal of Advertising, 27(3), 381-398.

Morgan, N., Hastings, E., \& Pritchard, A. (2012). Developing a new DMO marketing evaluation framework. Journal of Vacation Marketing, 18(1), 73-89. doi: 10.1177/1356766711432225

Naspetti, S., Pierdicca, R., Mandolesi, S., Paolanti, M., Frontoni, E., \& Zanoli, R. (2016). Automatic Analysis of Eye-Tracking Data for Augmented Reality Applications: A Prospective Outlook. Paper presented at the International Conference on Augmented Reality, Virtual Reality and Computer Graphics.

Neill, J., Hurwitz, D., \& Olsen, M. J. (2015). Alternative information signs: evaluation of driver comprehension and visual attention. Journal of transportation engineering, 142(1), 1-12.

Nelson, D., Graham, D., \& Harnack, L. (2014). An objective measure of nutrition facts panel usage and nutrient quality of food choice. Journal of Nutrition Education and Behavior, 46(6), 589-594.

Netek, R. (2011). Implementation of Ria concept and Eye tracking system for cultural heritage. Opgeroepen op september, 9, 2012-2019. 
Nevelsteen, K. (2013). Attention allocation of traffic environments of international visitors during virtual city walks. Paper presented at the Eye Tracking for Spatial Research, Proceedings of the 1st International Workshop (in conjunction with COSIT 2013).

Noone, B., \& Robson, S. (2014). Using Eye Tracking to Obtain a Deeper Understanding of What Drives Online Hotel Choice. Cornell Hospitality Report, 14(18), 6-16.

Noone, B., \& Robson, S. (2016). Understanding Consumers' Inferences from Price and Nonprice Information in the Online Lodging Purchase Decision. Service Science, 8(2), 108-123.

Orquin, J., \& Loose, S. (2013). Attention and choice: A review on eye movements in decision making. Acta psychologica, 144(1), 190-206.

Ozdemir, B., \& Caliskan, O. (2015). Menu Design: A Review of Literature. Journal of Foodservice Business Research, 18(3), 189-206. doi: 10.1080/15378020.2015.1051428

Pan, B., Hembrooke, H., Gay, G. K., Granka, L., Feusner, M., \& Newman, J. (2004). The determinants of web page viewing behavior: an eye-tracking study. Paper presented at the Proceedings of the 2004 symposium on Eye tracking research \& applications, New York.

Pan, B., Zhang, L., \& Law, R. (2013). The complex matter of online hotel choice. Cornell Hospitality Quarterly, 54(1), 74-83.

Pan, B., Zhang, L., \& Smith, K. (2011). A mixed-method study of user behavior and usability on an online travel agency. Information Technology \& Tourism, 13(4), 353-364.

Pieters, R., Hans, B., \& Allen, D. (1995). A means-end chain approach to consumer goal structures. International Journal of Research in Marketing, 12, 227-244.

Pieters, R., Rosbergen, E., \& Wedel, M. (1999). Visual Attention to Repeated Print Advertising: A Test of Scanpath Theory. Journal of marketing Research, 36(4), 424-438. doi: $10.2307 / 3151998$

Pieters, R., \& Warlop, L. (1999). Visual attention during brand choice: The impact of time pressure and task motivation. International Journal of Research in Marketing, 16(1), 1-16.

Pieters, R., \& Wedel, M. (2004). Attention capture and transfer in advertising: Brand, pictorial, and text-size effects. Journal of Marketing, 68(2), 36-50.

Pieters, R., \& Wedel, M. (2007). Goal control of attention to advertising: The Yarbus implication. Journal of Consumer Research, 34(2), 224-233.

Posner, M. (1980). Orienting of attention. Quarterly journal of experimental psychology, 32(1), 325. 
Potocka, I. (2013). The lakescape in the eyes of a tourist. Quaestiones Geographicae, 32(3), 8597.

Rayner, K. (1998). Eye movements in reading and information processing: 20 years of research. Psychological bulletin, 124(3), 372-422.

Rayner, K., Rotello, C., Stewart, A., Keir, J., \& Duffy, S. (2001). Integrating text and pictorial information: eye movements when looking at print advertisements. Journal of Experimental Psychology: Applied, 7(3), 219-226.

Ro, T., Friggel, A., \& Lavie, N. (2007). Attentional biases for faces and body parts. Visual Cognition, 15(3), 322-348. doi: 10.1080/13506280600590434

Robson, S., \& Noone, B. (2014). Show me what you see, tell me what you think: Using eye tracking for hospitality research Cornell Hospitality Report. Ithaca, NY: The Center for Hospitality Research, Cornell University.

Rosa, P. (2015). What do your eyes say? Bridging eye movements to consumer behavior. International Journal of Psychological Research, 8(2), 91-104.

Salvucci, D., \& Goldberg, J. (2000). Identifying fixations and saccades in eye-tracking protocols. Paper presented at the Proceedings of the 2000 symposium on Eye tracking research \& applications, Florida, USA.

Samant, S., \& Seo, H. (2016). Effects of label understanding level on consumers’ visual attention toward sustainability and process-related label claims found on chicken meat products. Food Quality and Preference, 50, 48-56.

Sang, Å., Tveit, M., Pihel, J., \& Hägerhäll, C. (2016). Identifying cues for monitoring stewardship in Swedish pasture landscapes. Land Use Policy, 53, 20-26.

Scott, N., Green, C., \& Fairley, S. (2016). Investigation of the use of eye-tracking to examine tourism advertising effectiveness. Current Issues in Tourism, 19(7), 634-642.

Scott, N., \& Smith, A. (2005). Use of automated content analysis techniques for event image assessment. Tourism Recreation Research, 30(2), 87-91.

Siegel, W., \& Ziff-Levine, W. (1990). Evaluating Tourism Advertising Campaigns : Conversion vs . Advertising Tracking Studies. Journal of Travel Research, 28(3), 51-55.

Sivaji, A., Tzuaan, S., Yang, L., \& bin Ali Russin, M. (2014). Hotel photo gallery and Malaysian travelers: preliminary findings. Paper presented at the User Science and Engineering (iUSEr), 2014 3rd International Conference on. 
Steciuk, H., \& Zwierko, T. (2015). Gaze behavior in basketball shooting: Preliminary investigations. Trends in Sport Sciences, 22(2), 89-94.

Tatler, B. (2009). Current understanding of eye guidance. Visual Cognition, 17(6-7), 777-789. doi: 10.1080/13506280902869213

Toyama, T., Kieninger, T., Shafait, F., \& Dengel, A. (2011). Museum guide 2.0-an eye-tracking based personal assistant for museums and exhibits. Paper presented at the Proc. of Int. Conf. on Re-Thinking Technology in Museums.

Tzuaan, S., Sivaji, A., Yong, L., Zanegenh, M., \& Shan, L. (2014). Measuring Malaysian Mcommerce user behaviour. Paper presented at the Computer and Information Sciences (ICCOINS), 2014 International Conference on.

Venkatraman, V., Dimoka, A., Pavlou, P., Vo, K., Hampton, W., Bollinger, B., . . W Winer, R. (2015). Predicting Advertising Success Beyond Traditional Measures: New Insights from Neurophysiological Methods and Market Response Modeling. Journal of marketing Research, 52(4), 436-452.

Vosskuhler, A., Nordmeier, V., Kuchinke, L., \& Jacobs, A. (2008). OGAMA (Open Gaze and Mouse Analyzer): open-source software designed to analyze eye and mouse movements in slideshow study designs. Behavior research methods, 40(4), 1150-1162.

Wang, Y., \& Sparks, B. (2016). An Eye-Tracking Study of Tourism Photo Stimuli: Image Characteristics and Ethnicity. Journal of Travel Research, 55(5), 588-602. doi: 10.1177/0047287514564598

Wedel, M., \& Pieters, R. (2008a). Eye tracking for visual marketing: Now Publishers Inc.

Wedel, M., \& Pieters, R. (2008b). A review of eye-tracking research in marketing. Review of marketing research, 4(2008), 123-147.

Wolfson, J., Graham, D., \& Bleich, S. (2017). Attention to Physical Activity-Equivalent Calorie Information on Nutrition Facts Labels: An Eye-Tracking Investigation. Journal of Nutrition Education and Behavior, 49(1), 35-42.

Yang, E., Khoo-Lattimore, C., \& Arcodia, C. (2017). A systematic literature review of risk and gender research in tourism. Tourism Management, 58, 89-100.

Yang, S. (2012). Eye movements on restaurant menus: A revisitation on gaze motion and consumer scanpaths. International Journal of Hospitality Management, 31(3), 1021-1029. doi: 10.1016/j.ijhm.2011.12.008. 